\title{
Ex ante assessment of the sustainability of alternative cropping systems: implications for using multi-criteria decision-aid methods. A review
}

\author{
Walid SADOK $^{1}$, Frédérique ANGEVIN ${ }^{2}$, Jacques-Éric BERGEZ ${ }^{3}$, Christian BocKSTALLER $^{4}$, Bruno COLOMB ${ }^{3}$, \\ Laurence GUICHARD ${ }^{1}$, Raymond REAU ${ }^{1}$, Thierry DORÉ ${ }^{1 *}$ \\ ${ }^{1}$ INRA, UMR211 INRA/AgroParisTech, BP 01, 78850 Thiverval-Grignon, France \\ ${ }^{2}$ INRA, UAR Eco-Innov, BP 01, 78850 Thiverval-Grignon, France \\ ${ }^{3}$ INRA, UMR1248 AGIR INRA/ENSAT, BP 52627, Auzeville, 31326 Castanet Tolosan, France \\ ${ }^{4}$ INRA, UMR INPL-(ENSAIA)-INRA Nancy-Colmar, BP 20507, 68021 Colmar, France
}

(Accepted 10 September 2007)

\begin{abstract}
Sustainability is a holistic and complex multi-dimensional concept encompassing economic, social and environmental issues, and its assessment is a key step in the implementation of sustainable agricultural systems. Realistic assessments of sustainability require: (1) the integration of diverse information concerning economic, social and environmental objectives; and (2) the handling of conflicting aspects of these objectives as a function of the views and opinions of the individuals involved in the assessment process. The assessment of sustainability is therefore increasingly regarded as a typical decision-making problem that could be handled by multi-criteria decision-aid (MCDA) methods. However, the number and variability of MCDA methods are continually increasing, and these methods are not all equally relevant for sustainability assessment. The demands for such approaches are also rapidly changing, and faster ex ante assessment approaches are required, to address scales currently insufficiently dealt with, such as cropping system level. Researchers regularly carry out comparative analyses of MCDA methods and propose guidelines for the selection of a priori relevant methods for the assessment problem considered. However, many of the selection criteria used are based on technical/operational assumptions that have little to do with the specificities of ex ante sustainability assessment of alternative cropping systems. We attempt here to provide a reasoned comparative review of the main groups of MCDA methods, based on considerations related to those specificities. The following main guidelines emerge from our discussion of these methods: (1) decision rule-based and outranking qualitative MCDA methods should be preferred; (2) different MCDA tools should be used simultaneously, making it possible to evaluate and compare the results obtained; and (3) a relevantly structured group of decision-makers should be established for the selection of tool variants of the choosen MCDA methods, the design/choice of sustainability criteria, and the analysis and interpretation of the evaluation results.
\end{abstract}

multi-criteria decision aid / cropping system / sustainability assessment / qualitative information / decision rules / outranking qualitative methods

\section{INTRODUCTION}

The precise meaning of Sustainable Agriculture is far from clear (e.g., Hansen, 1996; Smith and McDonald, 1998; Pannell and Schilizzi, 1999; Rigby and Caceres, 2001), but efforts have been made to produce an integrated definition of this term. According to Ikerd (1993), Sustainable Agriculture should be capable of maintaining its productivity and usefulness to society in the long term. This implies that it must be environmentally sound, resource-conserving, economically viable and socially supportive. Based on this definition, economic, environmental and social objectives should be analyzed as the principal dimensions of sustainability when sustainable practices are implemented in a given agricultural system (Schaller, 1993; Vereijken, 1997; den Biggelaar and Suvedi, 2000; Gafsi et al., 2006). If these objectives are to be considered together, then knowledge and research from relevant disciplines must be

* Corresponding author: thierry.dore@agroparistech.fr integrated while handling a mixture of multiple long-, shortterm, interacting and potentially conflicting goals, depending on the scale on which sustainability is considered (farm, landscape, region, nation, group of nations or global; Kruseman et al., 1996; Meyer-Aurich, 2005).

Assessing the sustainability of agricultural systems is a key issue for the implementation of policies and practices aiming at revealing sustainable forms of land use (Neher, 1992; Sulser et al., 2001; Pacini et al., 2003). However, if they are to be realistic and effective, such assessments must handle the complexity of the concept of "sustainability", as described above, whilst taking personal and subjective views concerning the relative importance of priorities into account (Dent et al., 1995; Park and Seaton, 1996; Andreoli and Tellarini, 2000). The assessment of sustainability is therefore increasingly regarded as a typical decision-making problem, leading to the development, by some researchers, of sustainability assessment decision-aid methods. Most of these approaches 
are based on multi-criteria decision-aid (or making) methods (MCDA or MCDM), and some have resulted in prototype sustainable solutions in the field (Rossing et al., 1997; Zander and Kächele, 1999; Loyce et al., 2002a,b; Dogliotti et al., 2005).

However, in practice, such assessments are confronted with two major problems. Firstly, the number of MCDA methods and tools available is continually increasing (Bouyssou et al., 1993, 2000, 2006), and studies aiming to assess the sustainability of agricultural systems rarely justify clearly their choice of one MCDA method over another. Only a few studies have presented a comparative, or at least exploratory, evaluation of the principal MCDA approaches available, in terms of the relevance to the purposes of the assessment. In contrast, many authors have concluded that, in typical decisionaid problems, there is rarely one ideal method and a group of MCDA methods should therefore be applied (Salminen et al., 1998; Zanakis et al., 1998; Macharis et al., 2004; Wang and Triantaphyllou, 2006). Moreover, the guidelines emerging from comparative studies are generally developed within the operational research community, based on technically oriented arguments and criteria from this field of research (see Guitouni and Martel, 1998 for review) without considering constraints related to the application domain. It should also be noticed that although some general guidelines, concerning specific features of sustainability assessment in most cases, have been developed (Rehman and Romero, 1993; Munda et al., 1994, 1995; Munda, 2005), they are still rarely followed explicitly in realcase contexts.

Secondly, demand is increasing among farmers' groups and policy-makers for more innovative sustainability assessment, highlighting a need for (i) faster ex ante assessment approaches for rapidly identifying alternative systems without assessing the entire initial systems in the field (European Commission, 2005; Van Ittersum et al., 2007), and (ii) the expansion of sustainability assessment to scales rarely studied at the moment, such as the cropping system scale. Indeed, most published studies have been carried out on a plot scale or on an even larger scale: farm, landscape, state or nation (Bontkes and van Keulen, 2003; Meyer-Aurich, 2005). A cropping system consists of a set of management procedures applied to a given, uniformly treated agricultural area, which may be a field, part of a field or a group of fields (Sebillotte, 1990). A given farming system may therefore be composed of a group of cropping systems, the sustainability assessment of which is potentially relevant, as they represent different, uniformly treated units. However, few published studies have described sustainability assessment explicitly at the level of the cropping system, with a given MCDA method (Mazzetto and Bonera, 2003), and those dealing with assessments at this level carried out no initial comparative assessment of MCDA methods.

The major aim of the paper is to provide a comparative review of the main families of MCDA methods, based on criteria related to the specificities of the sustainability assessment, for the a priori selection of groups of candidate MCDA methods for ex ante assessment of the sustainability of alternative cropping systems. Fine-tuning the selection process to the scale of individual methods is beyond the scope of our review, as there are dozens of algorithms/tools available in the literature and probably as many selection criteria which are set in a more technical background. A second aim of the study is thus to provide suggestions regarding the participatory process to be followed by the decision-makers, starting from the final MCDA tool choice to the analysis/interpretation of the ex ante assessment results.

\section{OVERVIEW AND TAXONOMY OF MULTIPLE CRITERIA DECISION-AID METHODS}

Multiple-criteria decision aid (MCDA) is a research area within the field of decision analysis (DA), which aims to develop methods and tools to assist with decision-making, particularly in terms of the choice, ranking or sorting of options (i.e., alternatives, solutions, courses of action, etc.), in the presence of multiple, and often conflicting criteria (Zanakis et al., 1998; Figueira et al., 2005). MCDA methodology can be seen as a non-linear recursive process including four main steps: (i) structuring the decision problem, (ii) articulating and modeling the preferences, (iii) aggregating the alternative evaluations (preferences), and (iv) making recommendations (Roy, 1985; Maystre et al., 1994).

MCDA methods have developed considerably over the last 30 years, resulting in a large number of methods and tools (Figueira et al., 2005). This has resulted in a need for the comparison of MCDA methods, to identify the most appropriate methods for the decisional problem considered (Zanakis et al., 1998; Brunner and Starkl, 2004). Many authors have stressed the need for a taxonomy of MCDA methods, as a starting point for the selection process (MacCrimmon, 1973; Hwang and Yoon, 1981). Dozens of taxonomies are currently available, based on a number of criteria, including:

- The number of alternatives considered: discrete vs. continuous distribution of alternatives (Schärlig, 1985; Maystre et al., 1994);

- Information measurement level of criteria - qualitative vs. quantitative, and the level of uncertainty (Munda et al., 1994, 1995);

- The methods used to construct the preference model: mathematical decision analysis approach vs. artificial intelligence approach (Nijkamp and Vindigni, 1998; Figueira et al., 2005);

- The criteria aggregation mode: complete, partial or local aggregation (Schärlig, 1985; Maystre et al., 1994; Vincke, 1989);

- The degree of compensation between the criteria (Hayashi, 2000);

- The descriptive, prescriptive, constructive or normative nature of decision-making (Bouyssou et al., 2006).

One of the most integrative taxonomies was established by Hwang and Yoon (1981). This taxonomy distinguished between multiple-objective decision-making (MODM) and multiple-attribute decision-making (MADM) methods, within the MCDA area. MODM methods can be used in cases in which there are an infinite (continuous) or large number of alternatives. They are based on multiple-objective mathematical 
programing models, in which a set of conflicting objectives is optimized and subjected to a set of mathematically defined constraints, for selection of the "best" alternative. MADM methods are used in cases of discrete, limited numbers of alternatives, characterized by multiple conflicting attributes (criteria). They are based on (i) the aggregation of judgments for each criterion and alternative, and (ii) the ranking of the alternatives according to the aggregation rules. MCDA, as used in many published studies, generally refers only to MADM, mainly because of the great number of methods of this type available. Indeed, a review of the literature spanning the last 25 years revealed an increasing number of new and hybrid MADM methods, leading to a great variability in taxonomies (Schärlig, 1985; Roy, 1985; Vincke, 1989; Nijkamp et al., 1990; Roy and Bouyssou, 1993; Maystre et al., 1994; Bouyssou et al., 2000, 2006; Figueira et al., 2005). Nevertheless, a synthesis of these taxonomies revealed that a majority of the most used MADM methods can fall into one of the following three categories: (i) multi-attribute utility methods, (ii) outranking methods, and (iii) mixed methods. The boundaries of the latter remain fuzzy in the reviewed literature to a point that led us to provide our own understanding of the term (see Sect. 3.1. for discussion).

\subsection{Multi-attribute utility methods}

These methods are essentially based on multi-attribute utility theory (MAUT, Keeney and Raiffa, 1976), which emerges from the philosophical doctrine of Utilitarism. If the decision is made in conditions in which the attributes are known with certainty (deterministic approach), the term "utility" is replaced by "value" (MAVT). The term "utility" is preferred to indicate that the preferences of stakeholders against risk are formally included in the analytical procedure. The MAUT method has three major steps: (i) normalization and evaluation of the performance of each alternative in terms of its utility, (ii) identification of the weights statistically representing the decision-maker's priorities for each criterion, and (iii) aggregation (based on additive, multiplicative, or other distributional formalisms, Guitouni and Martel, 1998) and ranking of the various alternatives.

The analytic hierarchy process (AHP) is another major approach first developed by Saaty (1980), based on the same aggregation principles as MAUT, but differs from the latter with respect to the way the decisional problem is handled. The AHP comprises four major steps:

1. Disaggregating a complex problem into a hierarchy, in which each level consists of specific elements. The overall objective of the decision lies at the top of the hierarchy, and the criteria, sub-criteria and decision alternatives are placed at descending levels in this hierarchy.

2. Pair-wise comparisons between all elements at the same level, based on a method converting verbal and subjective assessments into a set of overall scores or weights. The conversion depends on the decision-maker's answers to questions of the general form: "How important is criterion A relative to criterion B?" A verbal scale is then used to translate the response into a score from 1 to 9 . All pair-wise comparisons between single objects are used to constitute a pair-wise comparison matrix.

3. Checking the consistency of the matrix and deriving priorities from it.

4. Aggregation of criteria, with the help of a given additive or multiplicative utility function.

\subsection{Outranking methods}

Outranking methods are based on social choice theory. These methods lack the axiomatic basis of multi-attribute utility methods, but are useful in practice (Guitouni and Martel, 1998). "Outranking" is a concept originally developed by Roy (1985). It involves comparisons between every possible pair of options considered, to define binary relationships, such as "alternative $a$ is at least as good as alternative $b$ ". Procedures based on outranking have two phases. Decision-makers first provide information about their preferences for individual criteria, in the form of indifference and preference thresholds. Partial binary relationships are then calculated for all criteria, taking into account the inter-criterion preferences expressed in terms of weightings denoting relative importance. These weightings do not represent a trade-off between criteria scores (as in MAUT-based methods), as they are used to combine preference relationships rather than scores of alternatives. The ELECTRE method (Élimination et choix traduisant la réalité; Roy, 1968) was the first to use an outranking approach. It was followed by many others, including different versions of ELECTRE (II, III, IV, IS and TRI; Maystre et al., 1994) and the PROMETHEE methods (preference ranking organization method for enrichment evaluations; Brans, 1982). These methods are based on different preference structures.

\subsection{Mixed methods}

Many approaches other than the MADM methods described above have been proposed. Some have been referred to as "non-classical" or mixed. There seems to be no common definition of these terms within the MCDA community (see Munda et al., 1994; Maystre et al., 1994; Guitouni and Martel 1998; Figueira et al., 2005 for comparative review), but we understand these terms to correspond to a group of MADM methods (i) able to handle mixed qualitative-quantitative or qualitative criteria information explicitly, and/or (ii) with a preference model different from those classically used for multi-attribute utility and outranking methods.

A first major group of mixed MADM methods consists of outranking approaches handling qualitative or mixed information (Munda et al., 1994; Guitouni and Martel, 1998). There are many variants among this group, such as the REGIME methods (Nijkamp et al., 1990), QUALIFLEX (Paelink, 1978), ORESTE (Roubens, 1982), EVAMIX (Voogd, 1983), MELCHIOR (Leclerc, 1984) and ARGUS (de Keyser and Peters, 1994). 
A second group consists of decision rule-based approaches, which are often generically referred to as 'expert systems' (Kim et al., 1990). These methods were initially developed for the assessment of complex situations that cannot be handled through preference models based on conventional mathematical tools (means, sums, simple weighting and complex models; Tixier et al., 2007). In these methods, the preference model can be constructed through learning from examples. The global preference is defined by sorting the objects of analysis into predefined categories (e.g. acceptance, rejection, etc.) through a set of logical statements, typically representing "if/then" decision rules, which are often organized in the form of decision trees or decision tables. These decision rules are formulated on the basis of expert factual-heuristic knowledge (derived from interviews and literature) and/or with the help of data-mining and knowledge discovery tools (Kim et al., 1990; Pawlak, 1991; Zupan et al., 1999).

\section{SELECTION OF MULTIPLE CRITERIA DECISION-AID METHODS FOR EX ANTE ASSESSMENT OF THE SUSTAINABILITY OF CROPPING SYSTEMS}

\subsection{Relevance of MODM methods}

Most of the decision-aid approaches developed for assessing the sustainability of agricultural systems have classically been based on multiple-objective decision-making methods (MODM) (Meyer-Aurich, 2005). These methods are often implemented within some "systems approach" frameworks consisting of (i) systematic and quantitative analysis of agricultural systems for the mathematical definition of objectives and constraints, and (ii) the synthesis of optimal "solutions", using optimization techniques (Rossing et al., 1997; Zander and Kächele, 1999; ten Berge et al., 2000; Kropff et al., 2001; Hengsdijk and van Ittersum, 2002; Bontkes and van Keulen, 2003; Dogliotti et al., 2005). The ex ante evaluation of innovative cropping system sustainability poses two major problems for MODM methods based on optimization techniques:

(i) These methods are known to be sensitive to missing, inconsistent or mixed (quantitative and qualitative) data (Dent et al., 1995; Weersink et al., 2002; Dogliotti et al., 2005). In typical ex ante assessments of sustainability particularly on the cropping system scale, the assessment of which has not been extensively documented - there is unlikely to be sufficient scientific and/or expert quantitative knowledge available. Furthermore, as innovative demands cannot generally be systematically translated into scientific and/or quantitative data, the use of qualitative information in the assessment process is likely to be necessary. In addition, the use of qualitative data is increasingly considered a rule rather than an exception for the realistic assessment of the holistic environmental and socioeconomic issues underlying sustainability (Maystre et al., 1994; Munda et al., 1995). (ii) These methods are mostly required in cases in which "infinite" alternatives must be assessed to identify the "optimal" option (Steuer, 1986; Zhou et al., 2006). In our case, we are more likely to be assessing a finite number of alternative cropping systems, ranking them in terms of their potential sustainability. Such rankings allow a more extensive comparative analysis of the outputs of different assessment methods, potentially identifying promising alternatives not initially highly ranked.

Both these issues highlight the need for more appropriate and realistic approaches to the ex ante assessment of sustainability on the scale of the cropping system. The specificity of the sustainability assessment problem, with the implied need for MCDA approaches other than classical MODM methods, has already been highlighted by many authors (Voogd, 1983; Nijkamp et al., 1990; Munda et al., 1994; Nijkamp and Vindigni, 1998). Below, we will define selection criteria for identifying the most relevant of these methods for our purpose.

\subsection{Criteria for selecting relevant MADM methods}

We consider here two groups of criteria for identifying relevant approaches from the many MADM methods, based on the recommendations of Munda et al. (1994, 1995): (i) the ability of these methods to handle the typical multi-dimensional characteristics of sustainability assessment, and (ii) their ability to handle mixed measurement levels of criteria.

The need for methods to handle multi-dimensional characteristics translates operationally into three requirements: (i) incommensurability - an absence of the need for a common measure aggregating several dimensions, (ii) noncompensation - an advantage in one dimension of the evaluation is not totally offset by a disadvantage, and (iii) incomparability - the method does not offer a single comparative term by which all alternatives could be ranked (Schärlig, 1985; Maystre et al., 1994; Stewart and Losa, 2003). In realistic evaluations of the sustainability of agricultural systems, tackling environmental, social and economic dimensions, translates then into the fact that strong assumptions about the commensurability, compensation and comparability of values may not be relevant, as the criteria for different sustainability dimensions may have different units with low levels of trade-off (O'Neill, 1997; Martinez-Alier et al., 1998). The notions of commensurability, compensation and comparability are interconnected, in that strong commensurability implies full compensation of criteria and a high level of comparability of the actions considered. They are therefore not considered here to be independent selection criteria.

The second recommendation concerns the ability of these methods to handle heterogeneous measurement levels of criteria information (i.e., quantitative vs. qualitative) and their uncertainty (Munda et al., 1994, 1995). We will not consider the ability of MADM methods to handle uncertainty in this review. This criterion does not seem to be discriminatory, as almost all MADM and MODM methods can be linked to a procedure handling fuzzy or stochastic uncertainty (Chen and Huang, 


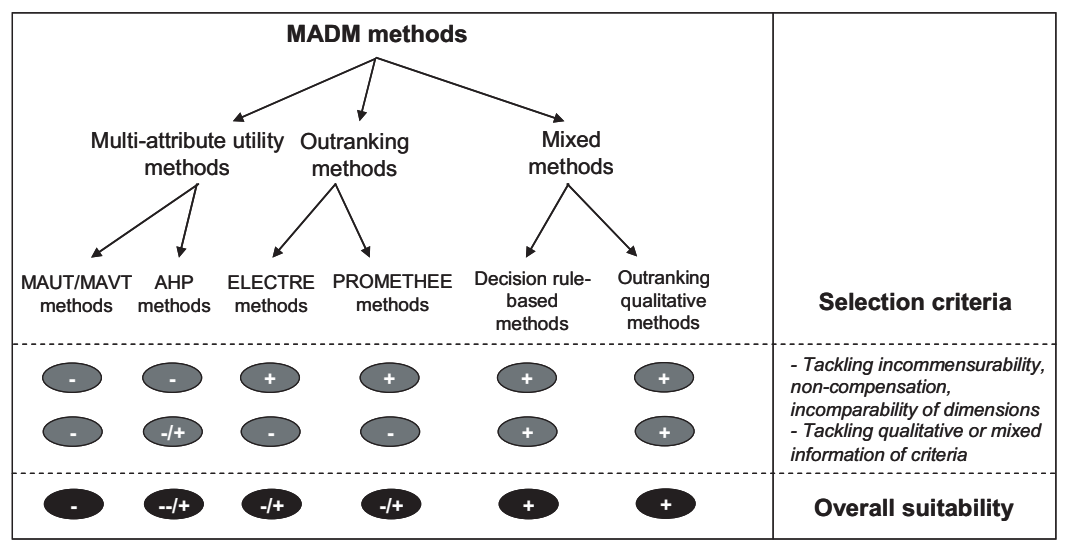

Figure 1. Taxonomy of multiple-attribute decision-making (MADM) methods and selection criteria used for the identification of suitable approaches for ex ante assessment of the sustainability of alternative cropping systems.

Gray symbols are given $(-;--/+; /-/+;+)$ to indicate the a priori irrelevance, partial relevance or relevance, respectively, of each group of methods based on the selection criteria considered. Overall assessments are given for each group of methods, in the form of dark symbols $(-;-/+;-/+;+)$ indicating the overall level of suitability (ranging from non-suitable to suitable) for ex ante assessment of the sustainability of alternative cropping systems. MAUT: multi-attribute utility theory; MAVT: multi-attribute value theory; AHP: analytic hierarchy process; ELECTRE: élimination et choix traduisant la réalité; PROMETHEE: preference ranking organization method for enrichment evaluations.

1992; Munda et al., 1995; Ertugrul Karsak, 2004). The suitability of each of the MADM methods considered will therefore be assessed for the interconnected characteristics of incommensurability, non-compensation and incomparability, together with their ability to handle qualitative or mixed criteria explicitly. Based on these criteria, we discuss in detail below the assessment process for each of the 3 groups of considered MADM methods identified in Section 1. The results are summarized in Figure 1.

\subsubsection{Multi-attribute utility methods}

Classical MAUT/MAVT methods are based on (i) a totally compensatory aggregation of criteria, and (ii) commensurable judgments, resulting in high levels of trade-off between criteria. Consequently, it is difficult, with most of these methods, to take into account the incommensurable and partly compensatory criteria that often underlie the dimensions of sustainability in agricultural systems (Rehman and Romero, 1993). Furthermore, these methods do not take qualitative or mixed (qualitative and quantitative) criteria into account efficiently and explicitly (Munda et al., 1994). Consequently, although some authors have reported the use of MAUT methods for some agricultural and environmental assessments (Salminen et al., 1998; Hayashi, 2000), these models may be considered inappropriate for assessment of the sustainability of alternative cropping systems, according to our objectives (Fig. 1).

AHP methods offer alternative advantages compared with classical multi-attribute utility methods, consisting of (i) the hierarchical decomposition of the decisional problem, and (ii) the use of subjective and verbal expressions to define the relative importance of the criteria (Macharis et al., 2004). Some authors consider most AHP models to be able to handle missing quantitative data and a lack of precision, based on the judgment and experience of decision-makers, making it possible to prioritize information to improve decisions (Alphonce, 1997). This may explain why AHP is the most used MAUT-based method for solving agro-environmental decisional problems, mainly ex ante. Indeed, some authors have used AHP models to choose crops so as to determine the best allocation of resources (Alphonce, 1997), to evaluate soil productivity (Zhang et al., 2004) and to assess the environmental, economic and social factors relating to the adoption of silvopasture techniques in south-central Florida (Shrestha et al., 2004). Other authors have used this method to rank alternatives for preserving or increasing social benefits from the sustainable use of natural resources, such as forestry management (Schmoldt, 2001), wetland management (Herath, 2004) and land preservation (Duke and Aull-Hyde, 2002).

The main drawbacks of the AHP method are potential internal inconsistency and the questionable theoretical basis of the rigid 1-9 scale, together with the possibility of rank reversal following the introduction of a new alternative (French, 1988; Goodwin and Wright, 1998; Macharis et al., 2004). Alternative methods, such as the MACBETH method (Bana e Costa and Vansnick, 1997) have been developed to overcome some of these objections. However, one of the most oftencited objections to AHP methods is the totally compensatory aggregation procedure, resulting in a high level of trade-offs between criteria (Roy and Bouyssou, 1993; Macharis et al., 2004). Thus, as for other MAUT approaches, the use of an AHP method may limit, to some extent, the possibility of taking into account incommensurable and partly compensatory criteria, which often underlie the concept of "sustainability", as applied to agricultural systems. Moreover, although the method uses verbal scales, it is not considered truly qualitative (Munda et al., 1994). Instead, it is described as semiqualitative (Ayalew et al., 2005) or purely quantitative (Moffett and Sarkar, 2006). Consequently, attention must be paid to these advantages and disadvantages if an AHP method is used 
alone for ex ante evaluation of the multi-dimensional sustainability of alternative cropping systems (Fig. 1).

\subsubsection{Outranking methods}

The key feature of outranking methods, due to the vague determination of preferences, is that they give low levels of comparability between options (i.e., performance not measured on the same cardinal scale), making it possible to deal with incommensurability (Maystre et al., 1994). This advantage may account for their widespread use in agricultural-environmental sustainability evaluation frameworks, on different scales, for dealing with problems of choice between alternatives. At policy level, the ELECTRE and PROMETHEE methods have been used to rank different projects for environmental conservation and the sustainable use of resources for several specific problems: irrigation management planning (Pillai and Raju, 1996), the conservation of multifunctional forests (Kangas et al., 2001), waste management (Salminen et al., 1998) and environmental quality (Rogers and Bruen, 1998). On the farm and cropping system scales, outranking methods have been used successfully more frequently than other MADM methodologies for various assessments. Van Huylenbroeck and Damasco-Tagarino (1998) used the PROMETHEE method to choose the best crops for the ideal cropping timetable for the farmer. Arondel and Girardin (2000) used an ELECTRE method to sort cropping systems on the basis of their impact on groundwater quality. Loyce et al. (2002a,b) developed an ELECTRE-based method (the BETHA system) for assessing winter wheat management plans with respect to a set of conflicting economic, environmental and technological requirements. Mazzetto and Bonera (2003) developed a multicriteria software package derived from the ELECTRE method (MEACROS), with the aim of identifying alternative cropping systems meeting a set of technical, economic and environmental criteria. These examples highlight the possibility of using outranking methods for ex ante evaluation of the sustainability of cropping systems, based on their ability to tackle the incommensurability, non-compensation and incomparability of the sustainability dimensions more efficiently than classical multiattribute utility methods. However, it has never been clearly stated that these outranking methods - in their strictest definition - are compatible with the use of explicitly qualitative or mixed (qualitative/quantitative) criteria. Consequently, this possible limitation should be borne in mind when selecting an appropriate outranking MADM method for the ex ante assessment of alternative cropping systems (Fig. 1).

\subsubsection{Mixed methods}

\section{Outranking qualitative methods}

Given the ability of these methods to tackle incommensurability, non-compensation and incomparability of the sustainability dimensions while handling qualitative criteria, they should be considered potentially relevant for ex ante assessment of the sustainability of cropping systems. However, it is noteworthy that though many of these methods, and especially the REGIME approach (Nijkamp et al., 1990), are regularly used for environmental planning and management purposes, such approaches are rarely applied in the agricultural sector. Nevertheless, the successful use of a REGIME method in a real case for evaluation of the sustainability of agricultural land use in terms of environmental, economic and social objectives reported by Hermanides and Nijkamp (1997) is another argument in favor of its use for ex ante assessment of the sustainability of cropping systems.

\section{Decision rule-based MADM methods}

These non-classical methods are considered potentially relevant for the solution of various agricultural decisional problems (Dent et al., 1995). Indeed, the decision rules approach (i) is intelligible and uses the language of the decision-maker, through symbolic qualitative variables, (ii) is based on transparently expressed preference information based on the observations, views and opinions of the decision-maker, and (iii) offers the possibility of handling inconsistencies in preferential information resulting from hesitation on the part of the decision-maker (Bontkes and van Keulen, 2003; Greco and Matarazzo, 2005). Moreover, decision rule-based methods can be used for the explicit handling of totally noncompensatory decision processes (Ma, 2006), making it easier to tackle incomparability and incommensurability (O'Neill, 1997; Martinez-Alier et al., 1998; Stewart and Losa, 2003). This makes the decision rule approach more flexible for the modeling of the decision process, as it takes into account a large diversity of considerations much more general than those taken into account by all other existing classical decision models used within the MCDA area (Figueira et al., 2005). However, according to Ma (2006), one of the main limitations of this approach is that, in some complex real-life situations, too many decision rules may be required to represent the decisional problem, making this technique cumbersome. Conversely, others would argue that in many real-life situations, particularly those concerning the decisions facing farm households, such approaches are far more realistic and practical than other classical MCDA methods (Dent et al., 1995). In any case, the level of complexity of the decision rules probably depends more on the specific features of the decisional problem considered than on the approach itself.

In agricultural contexts, decision rules have been used for the development of agri-environmental indicators for assessing the sustainability of cropping systems in terms of pesticide impact (van Der Werf and Zimmer, 1998; Ferraro et al., 2003; Tixier et al., 2007). Those authors combined their expert decision rules with fuzzy logic to cope with uncertainty and to avoiding the effect of a knife-edge limit for a given attribute. On the landscape scale, "classical" expert methods have been used to assess soil erosion risks (Cerdan et al., 2002) and biodiversity (Crist et al., 2000). Phillis and Andriantiatsaholiniainan (2001) have developed a more integrative conceptual methodology based on fuzzy expert decision rules for 
evaluating the sustainability of agricultural systems, according to their economic, ecological and social goals. However, this method did not focus explicitly on the cropping system scale, as it evaluated farming systems on regional and national scales. Agronomy researchers have recently begun to make use of expert tools initially designed for non-agricultural assessment purposes for assessing sustainability-related issues. For example, Bohanec et al. (2004) tested and established the a priori usefulness of the expert tool DEXi for evaluating the ecological and economic sustainability of cropping systems based on genetically modified maize (Bt-corn). Such expert tools may thus be relevant for ex ante evaluation of the sustainability of cropping systems (Fig. 1).

As summarized in Figure 1, this review revealed that the most suitable MADM methodologies for ex ante assessment of the sustainability of alternative cropping systems are of the "mixed" type (qualitative outranking and decision rule-based methods), followed by outranking methods, and then AHP methods, based on criteria presented at the beginning of Section 3.2.

\section{GENERAL DISCUSSION}

\subsection{Bibliographic survey and selection of MCDA methods: difficulties encountered}

In this work, we have discussed the pre-selection of families of MCDA methods according to their relevance for the ex ante assessment of the sustainability of alternative cropping systems. We had an idea concerning the strategy to be followed - identification of a relevant taxonomy of methods and of an appropriate set of selection criteria - but the selection process was nonetheless laborious. The laboriousness of pre-selection may explain why so few real-case studies include a comparative or explorative evaluation of the main groups of MCDA approaches available for the specific purposes of the assessment (Zanakis et al., 1998; Hayashi, 2000).

The main difficulty in this process was the identification of a relevant taxonomy of MCDA methods. A review of the literature published on MCDA over the last 25 years revealed that this research field has increased in diversity and complexity, leading to an increasing number of new and hybrid methods, resulting in turn in a large number of taxonomies (see Roy, 1985 and Figueira et al., 2005 for review). The result was that in work aiming at selecting relevant MCDA methods, the considered taxonomy was often found not to be independent of the views of the authors and the specific purposes of the assessment. This was also the case for more "conceptual" studies proposing formalized typological tree or expert system approaches for the selection of relevant MCDA methods, while initially based on a specifically established taxonomy and thus not appropriate for systematic generalization (Jelassi and Ozemoy, 1988; Guitouni and Martel, 1998). Another difficulty was that some of these taxonomies were conflicting and even, in some cases, contradictory. This was particularly true for the "mixed" category, the characteristics of which were highly variable, according to the authors' own understanding of this term. For instance, some authors considered the REGIME methods to be mixed (Munda et al., 1995), whereas others considered them to be simple classical outranking methods (Brunner and Starkl, 2004). Some authors consider the EVAMIX approach to be a mixed outranking method (Munda et al., 1994), whereas others consider this approach to be neither of the outranking nor of the mixed type (Guitouni and Martel, 1998). Similar discrepancies have also been observed regarding AHP methods, which are considered by some authors to be qualitative (Alphonce, 1997), whereas others explicitly consider them to be quantitative (Moffet and Sarkar, 2006). In each of these situations, our classification is based on the predominant view expressed in published studies, with particular weight given to classifications relating to agro-environmental or environmental sustainability assessment problems (Munda et al., 1994, 1995; Nijkamp and Vindigni, 1998).

\subsection{Relevance of the considered MCDA taxonomy and selection criteria}

As recommended by Zanakis et al. (1998), our selection was based on a taxonomy serving more as a tool for elimination than for selection of "the right method". Moreover, rather than using selection criteria based exclusively on technical/operational assumptions, we based our criteria on assumptions derived from more realistic situations, reflecting the specific features of the sustainability assessment, as recommended by Munda et al. (1994, 1995). These criteria were then translated into more technical criteria (incommensurability, incomparability, non-compensation; mixed information). Though the considered taxonomy and selection criteria are linked to the specific purpose of our assessment, these two initial steps might serve as guidelines for similar cases.

\subsubsection{MADM versus $M O D M$}

In our process for selecting potentially relevant MCDA methods for ex ante assessment of the sustainability of alternative cropping systems, we first considered one of the most integrative taxonomies within the MCDA area (MODM vs. MADM), to exclude the largest possible group of methods (see Sect. 3.1).

At that stage of MCDA method selection, we were confronted with two opposite approaches within the agricultural sustainability research community. Users of MODM methods claim that only such quantitative methods can disentangle the complex relationships between agricultural production, environment and economy, thereby increasing the transparency of choices regarding sustainability (Hengsdijk and van Ittersum, 2002). Similarly, others even consider that the use of expert rules and semi-quantitative indicators in such studies is cause for concern as it is difficult to evaluate such rules, rendering the results of local relevance at best, whereas MODM methods are more effective (Dogliotti et al., 2005). Conversely, some authors consider that realistic assessment of the holistic 
and uncertain issues of sustainability requires a method capable of handling qualitative information (Munda et al., 1994, 1995; Hermanides and Nijkamp 1997; Phillis and Andriantiatsaholiniainan, 2001). Based on these elements and the particular features of ex ante assessment of the sustainability of alternative cropping systems, as stated in Section 2.1, we have therefore discarded MODM methods in the selection process.

However, it should be pointed out that, although rejected in this study, some MODM methods have been used for ex ante assessments of alternative farming systems with respect to sustainability-related objectives (e.g., Dogliotti et al., 2004, 2005; Tré and Lowenberg-Deboer, 2005). In these cases, the innovative aspect of these systems consisted of the design of sustainable production activities, based on the optimization of an innovative combination of a limited set of quantitatively measurable criteria representing inputs and outputs. This is quite different from considering innovative sustainability issues and objectives directly translated into innovative criteria, some of which cannot be measured quantitatively. For instance, this would be the case for criteria related to (i) holistic issues such as biodiversity, or (ii) subjective considerations such as social wellbeing, which are not taken into account in those quoted studies using a MODM method. However, this does not mean that optimization approaches are necessarily unsuitable for purposes similar to ours. Indeed, within the mathematical programing area, optimization algorithms able to handle qualitative criteria have already been developed (Brewka, 2006). With new developments continually occurring in the MCDA field, these algorithms are likely to be integrated into MODM methods in the near future, making it possible for these methods to handle qualitative data. Our decision to reject MODM methods regarding our aims and the present state of the art should therefore not be regarded as definitive. It will be reconsidered regularly, based on surveys of future developments within the MCDA area.

\subsubsection{Selection from MADM methods}

In this study, we considered an integrative taxonomy of MADM methods, so many methods' variants did not find their way into this review. Indeed, our purpose was to discuss general guidelines for the selection of a relevant MADM method for ex ante assessment of the sustainability of alternative cropping systems, rather than a complete and exhaustive survey of the existing methods and their evaluation for this purpose. In our case, a more detailed comparative review of algorithm variants within each method group would extend far beyond the scope of this paper, as it would require more technical background information and fewer sustainability assessmentrelated considerations.

We did not consider here selection criteria based on the ability of the methods reviewed to tackle information uncertainty through fuzzy (and/or stochastic) procedures, for two main reasons. Firstly, the uncertainty criterion is not discriminatory, as all the reviewed methods could be coupled to such procedures. Secondly, some authors have argued that (i) there is a lack of convincing evidence that the imprecision captured through fuzzy sets could match the real fuzziness of perceptions that humans typically display with respect to the components of decision problems, and (ii) means of calibrating and manipulating fuzzy functions with a transparent rationale from the point of view of non-specialists are lacking (UK DTLR, 2001).

Some conceptual selection criteria used in some taxonomies were not considered in this work. For instance, we did not consider the mode of decision-making, which distinguishes between normative (postulation), descriptive (observation), prescriptive (unveiling) or constructive (reaching a consensus) methods (Bouyssou et al., 2006). Indeed, some authors have expressed the view that this classification is not really discriminatory, as in practice, methods initially considered normative may be used in a constructive, descriptive or prescriptive manner, depending on the context in which they are applied (Dias and Tsoukias, 2003). Nevertheless, to some extent, we have considered (besides criteria specific to ex ante sustainability assessment requirements) a decision-making mode-based selection approach when discarding MODM methods in favor of MADM ones. Indeed, the former aim at reaching one optimal (normative) 'solution' (i.e., a cropping system) whereas the latter allow for relative ranking of different ones (see Sect. 2.1), which fitted our objectives much more.

Other reported selection criteria based on operational assumptions, such as transparency, ease of use, profile of the decision-maker and number of decision-makers, were not taken into account in our review, as we consider that (i) some of these considerations depend more on the control and reporting capabilities of the corresponding software/tool than on the method itself, and (ii) these considerations are only loosely connected to the specific features of sustainability assessment (as described in Sect. 2.2). Such an assessment would - at least theoretically - address all levels of decision-makers, from stakeholders to policymakers. However, this does not mean that these aspects are of secondary importance in the process of ex ante evaluation of the sustainability of cropping systems. They are simply more relevant to consider in the steps following the pre-selection of relevant MADM methods (see section below).

\subsection{Recommended next steps}

The proposed ranking of candidate MADM methods (Fig. 1) should be considered as a starting point for effective ex ante assessment of the sustainability of alternative cropping systems in order to identify the ones that could be implemented in the field.

Ideally, the next sequence of steps should be closely monitored by a relevant group of decision-makers which should include researchers and other stakeholders who interact following a participatory/cooperative approach. This is essential to avoid a classical researcher-driven process toward a predetermined direction, which is risky especially for sustainability assessments as those address intrinsically holistic and subjective issues (Brunner and Starkl, 2004). This group of 


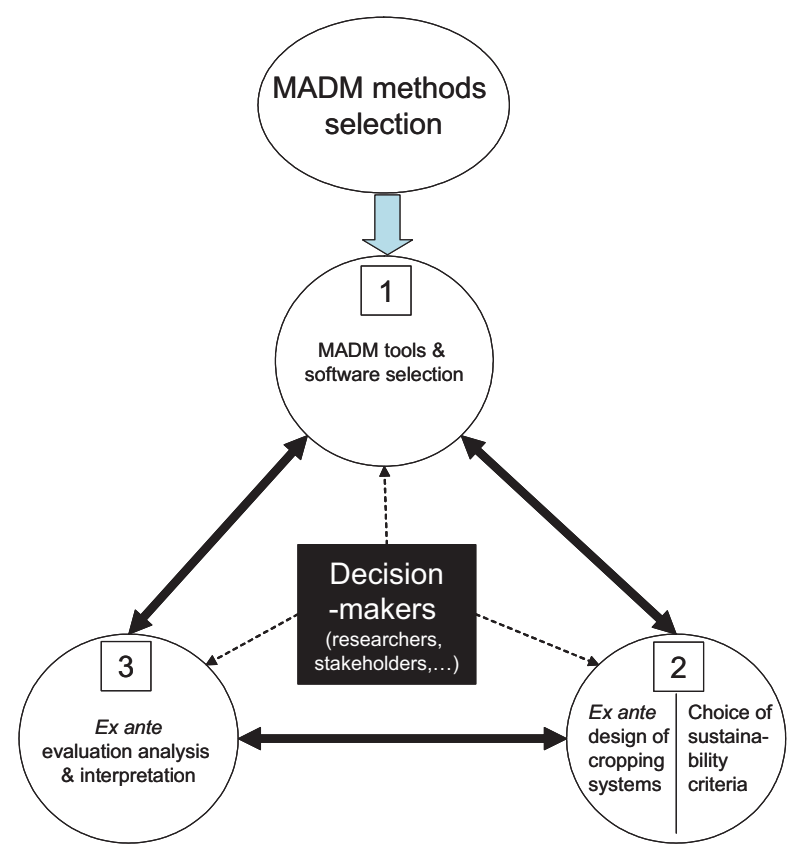

Figure 2. Suggested structure of the framework to be set up following the multi-criteria decision-aid (MADM) method selection process, in order to carry out ex ante assessment of the sustainability of cropping systems.

decision-makers should then work on the basis of a three-axis framework (Fig. 2), consisting of the following steps:

1. The collective selection of given decision-aid tools/software from the most suitable MADM method categories. Each MADM group being composed of numerous method variants and dozens of corresponding tools, a comparative (even restricted) assessment of these methods and tools might be necessary before selection. In order for the tool to be used by a large variety of decision-makers, the comparison should be based on operational and practical criteria, such as (i) the availability of the tool and its documentation, (ii) the time and manpower resources required for the analysis, and (iii) the ease of use, transparency and reporting capabilities of the tool (UK DTLR, 2001)

2. The collective ex ante design of the options (i.e., alternative cropping systems) to be evaluated based on vectors of sustainability criteria, with respect to the specific features of the MADM tool considered (Fig. 2). In this key step, it is essential that the knowledge and expertise of the decisionmakers encompasses the considered sustainability issues, in order to design (quantitatively and/or qualitatively) relevant sustainability criteria (e.g. groundwater pollution, erosion and compaction risks, impact on biodiversity, energy consumption, gross margin, health risks, etc.). In order for the group to promote the discovery/design of alternative sustainability criteria not obvious or apparent at first sight, a work strategy based on brainstorming tools such as lateral thinking, affinity diagrams and interrelationship diagraphs can be of importance (Baker et al., 2002).
3. The ex ante assessment of the designed cropping systems and the analysis/interpretation of the results by the decisionmakers based on the considered sustainability criteria and the characteristics of the applied MADM tools. Consistent with the recommendations of Zanakis et al. (1998), Macharis et al. (2004) and Wang and Triantaphyllou (2006), this multi-toolbased analysis may reveal alternative cropping systems that would be considered a priori sustainable, independently of the method applied. However, before the final selection of the options, it is recommendable to perform sensitivity and explanation analysis of the evaluation results obtained via each considered tool.

During all these steps, it is necessary to maintain a regular feedback with the operational research community, in order to ensure a cohesive operational framework.

Acknowledgements: This study was funded by the ANR (Agence Nationale de la Recherche) under the French Federator Program ADD (Agriculture et Développement Durable) via the Project DISCOTECH (Dispositifs innovants pour la conception et l'évaluation des systèmes techniques). We thank Olivier Crespo for his valuable comments on multi-criteria decision-aid methods.

\section{REFERENCES}

Alphonce C.B. (1997) Application of the analytic hierarchy process in agriculture in developing countries, Agr. Syst. 53, 97-112.

Andreoli M., Tellarini V. (2000) Farm sustainability evaluation: methodology and practice, Agr. Ecosyst. Environ. 77, 43-52.

Arondel C., Girardin P. (2000) Sorting cropping systems on the basis of their impact on groundwater quality, Eur. J. Oper. Res. 127, 467482.

Ayalew L., Yamagishi H., Marui H., Kanno T. (2005) Landslides in Sado Island of Japan: Part II. GIS-based susceptibility mapping with comparisons of results from two methods and verifications, Eng. Geol. 81, 432-445.

Baker D., Bridges D., Hunter R., Johnson G., Krupa J., Murphy J., Sorenson K. (2002) Guidebook to Decision-Making Methods, WSRC-IM-2002-00002, Department of Energy, USA.

Bana e Costa C.A., Vansnick J.C. (1997) Applications of the MACBETH approach in the framework of an additive aggregation model, J. Multi-Criteria Decision Anal. 6, 107-114.

Bohanec M., Džeroski S., Žnidaršiè M., Messean A., Scatasta S., Wesseler J. (2004) Multi-attribute modelling of economic and ecological impact of cropping systems, Informatica (Ljubljana, Slovenia) 28, 387-392.

Bontkes T.S., van Keulen H. (2003) Modelling the dynamics of agricultural development at farm and regional level, Agr. Syst. 76, 379396.

Bouyssou D., Perny P., Pirlot M., Tsoukias A., Vincke P. (1993) A manifesto for the new MCDA era, J. Multi-Criteria Decision Anal. 2, $125-127$.

Bouyssou D., Marchant T., Pirlot M., Perny P., Tsoukiàs A., Vincke P. (2000) Evaluation and decision models: a critical perspective, Kluwer Academic, Boston, London, Dordrecht.

Bouyssou D., Marchant T., Pirlot M., Tsoukias A., Vincke P. (2006) Evaluation decision models with multiple criteria. Stepping stones for the analyst, Springer Science + Business Media Inc., New York. 
Brans J.P. (1982) L'ingénierie de la décision ; Élaboration d'instruments d'aide à la décision. La méthode PROMETHEE, in: Nadeau R., Landry M. (Eds.), L'aide à la décision : Nature, Instruments et Perspectives d'Avenir, Presses de l'Université Laval, Québec, pp. 183-213.

Brewka G. (2006) Answer Sets and Qualitative Optimization, Logic Jnl. IGPL 14, 413-433.

Brunner N., Starkl M. (2004) Decision aid systems for evaluating sustainability: a critical survey, Environ. Impact. Assess. Rev. 24, 441469.

Cerdan O., Souchère V., Lecomte V., Couturier A., Le Bissonnais Y (2002) Incorporating soil surface crusting processes in an expertbased runoff and erosion model STREAM (Sealing Transfer Runoff Erosion Agricultural Modification), Catena 46, 189-205.

Chen S.J., Hwang C.L. (1992) Fuzzy Multiple Attribute Decision Making: Methods and Applications, Springer-Verlag, Berlin.

Crist P.J., Kohley T.W., Oakleaf J. (2000) Assessing land-use impacts on biodiversity using an expert systems tool, Landscape Ecol. 15, 4762.

de Keyser W., Peters P. (1994) ARGUS - a new multiple criteria method based on the general idea of outranking, in: Paruccini M. (Ed.), Applying multiple criteria aid for decision to environmental management, Kluwer, Dordrecht, pp. 263-278.

den Biggelaar C., Suvedi M. (2000) Farmers' definitions, goals, and bottlenecks of sustainable agriculture in the North-Central Region, Agr. Hum. Val. 17, 347-358.

Dent J.B., Edward-Jones G., McGregor M.J. (1995) Simulation of ecological, social, and economic factors in agricultural systems, Agr. Syst. 49, 337-351.

Dias L.C., Tsoukiàs A. (2003) On the constructive and other approaches in decision aiding, in: Henggeler Antunes C.A., Figueira J. (Eds.), Proceedings of the 57th Meeting of the EURO MCDA Working Group, University of Tuscia, Italy.

Dogliotti S., Rossing W.A.H., Van Ittersum M.K. (2004) Systematic design and evaluation of crop rotations enhancing soil conservation, soil fertility and farm income: a case study for vegetable farms in South Uruguay, Agr. Syst. 80, 277-302.

Dogliotti S., Van Ittersum M.K., Rossing W.A.H. (2005) A method for exploring sustainable development options at farm scale: a case study for vegetable farms in South Uruguay, Agric. Syst. 86, 29-51.

Duke J., Aull-Hyde R. (2002) Identifying public preferences for land preservation using the analytic hierarchy process, Ecol. Econ. 42, 131-145.

Ertugrul Karsak E. (2004) Fuzzy multiple objective decision making approach to prioritize design requirements in quality function deployment, Int. J. Prod. Res. 42, 3957-3974.

European Commission (2005) Impact assessment Guidelines, 15th of June 2005 with March 2006 Update, SEC (2005) 791.

Ferraro D.O., Ghersa C.M., Sznaider G.A. (2003) Evaluation of environmental impact indicators using fuzzy logic to assess the mixed cropping systems of the Inland pampa, Argentina, Agr. Ecosyst. Environ. 96, 1-18.

Figueira J., Greco S., Ehrgott M. (2005) (Eds.) Multiple Criteria Decision Analysis: State of the Art Surveys, Springer-Verlag, New York.

French S. (1988) Decision Theory: an Introduction to the Mathematics of Rationality, Ellis Horwood, Chichester.

Gafsi M., Legagneux B., Nguyen G., Robin P. (2006) Towards sustainable farming systems: Effectiveness and deficiency of the French procedure of sustainable agriculture, Agr. Syst. 90, 226-242.
Goodwin P., Wright G. (1998) Decision Analysis for Management Judgement, second edition, John Wiley, Chichester.

Greco S., Matarazzo B. (2005) Decision rule approach, in: Figueira J., Greco S., Ehrgott M. (Eds.), Multiple Criteria Decision Analysis: State of the Art Surveys, Springer-Verlag, New York.

Guitouni A., Martel J.M. (1998) Tentative guidelines to help choosing an appropriate MCDA method, Eur. J. Oper. Res. 109, 501-521.

Hansen J.W. (1996) Is agricultural sustainability a useful concept? Agr. Syst. 50, 117-143.

Hayashi K. (2000) Multicriteria analysis for agricultural resource management: a critical survey and future perspectives, Eur. J. Oper. Res. $122,486-500$.

Hengsdijk H., Van Ittersum M.K. (2002) A goal-oriented approach to identify and engineer land use systems, Agr. Syst. 71, 231-247.

Herath G. (2004) Incorporating community objectives in improved wetland management: the use of the analytic hierarchy process, J. Environ. Manage. 70, 263-273.

Hermanides G., Nijkamp P. (1997) Multicriteria evaluation of sustainable agricultural land use: a case of Lesvos, Research Memorandum 1997-5. Free University of Amsterdam, Faculty of Economics, Business Administration and Econometrics.

Hwang C.L., Yoon K.L. (1981) Multiple Attribute Decision Making: Methods and Applications, Springer-Verlag, New York.

Ikerd J.E. (1993) The need for a systems approach to sustainable agriculture, Agr. Ecosyst. Environ. 46, 147-160.

Jelassi M.T.J., Ozemoy V.M. (1988) A framework for building an expert system for MCDM models selection, in: Lockett A.G., Islei G. (Eds.), Improving Decision Making in Organzations, SpringerVerlag, New York, pp. 553-562.

Kangas J., Kangas A., Leskinen P., Pykäläinen J. (2001) MCDM methods in strategic planning of forestry on state-owned lands in Finland: applications and experiences, J. Multi-Criteria Decision Anal. 10, 257-271.

Keeney R., Raiffa H. (1976) Decisions with Multiple Objectives: Performances and Value Trade-Offs, Wiley, New York.

Kim T.L., Wiggins L., Wright J. (1990) (Eds.) Expert Systems: Applications to Urban Planning, Springer-Verlag, New York.

Kropff M.J., Bouma J., Jones J.W. (2001) Systems approaches for the design of sustainable agro-ecosystems, Agr. Syst. 70, 369-393.

Kruseman G., Ruben R., Kuyvenhoven A. (1996) Analytical framework for disentangling the concept of sustainable land use, Agr. Syst. 50, 191-207.

Leclerc J.P. (1984) Propositions d'extension de la notion de dominance en présence de relations d'ordre sur les pseudo-critères: MELCHIOR, Math. Social Sci. 8, 45-61.

Loyce Ch., Rellier J.P., Meynard J.M. (2002a) Management planning for winter wheat with multiple objectives (1): the BETHA system, Agr. Syst. 72, 9-31.

Loyce Ch., Rellier J.P., Meynard J.M. (2002b) Management planning for winter wheat with multiple objectives (2): ethanol-wheat production, Agr. Syst. 72, 33-57.

Ma L. (2006) Knowledge Representation Under Inherent Uncertainty in a Multi-Agent System for Land Use Planning, Ph.D. Thesis, Eindhoven University of Technology, Eindhoven, The Netherlands, $164 \mathrm{p}$.

MacCrimmon K.R. (1973) An overview of multiple objective decision making, in: Cochran J.L., Zeleny M. (Eds.), Multiple Criteria Decision Making, University of South Carolina Press, Columbia. 
Macharis C., Springael J., De Brucker K., Verbeke A. (2004) PROMETHEE and AHP: The design of operational synergies in multicriteria analysis. Strengthening PROMETHEE with ideas of AHP, Eur. J. Oper. Res. 153, 307-317.

Martinez-Alier J., Munda G., O’Neill J. (1998) Weak comparability of values as a foundation for ecological economics, Ecol. Econ. 26, $277-286$.

Maystre L.Y., Pictet J., Simos J. (1994) (Eds.) Méthodes multicritères ELECTRE, Presses Polytechniques et Universitaires Romandes, Lausanne.

Mazzetto F., Bonera R. (2003) MEACROS: a tool for multi-criteria evaluation of alternative cropping systems, Eur. J. Agron. 18, 379-387.

Meyer-Aurich A. (2005) Economic and environmental analysis of sustainable farming practices - a Bavarian case study, Agr. Syst. 86, 190-206.

Moffett A., Sarkar S. (2006) Incorporating multiple criteria into the design of conservation area networks: a minireview with recommendations, Diversity Distributions 12, 125-137.

Munda G., Nijkamp P., Rietveld P. (1994) Qualitative multicriteria evaluation for environmental management, Ecol. Econ. 10, 97-112.

Munda G., Nijkamp P., Rietveld P. (1995) Qualitative multicriteria methods for fuzzy evaluation problems: An illustration of economicecological evaluation, Eur. J. Oper. Res. 82, 79-97.

Munda G. (2005) Multiple criteria decision analysis and sustainable development, in: Figueira J., Greco S., Ehrgott M (Eds.), Multiple Criteria Decision Analysis: State of the Art Surveys, SpringerVerlag, New York.

Neher D. (1992) Ecological sustainability in agricultural systems, Definition and measurement, J. Sustain. Agr. 2, 51-61.

Nijkamp P., Rietveld P., Voogd H. (1990) Multicriteria Evaluation in Physical Planning, North-Holland, Amsterdam.

Nijkamp P., Vindigni G. (1998) Integrated Multicriteria Evaluation Methods for Sustainable Agricultural Policy Analysis, Riv. Econom. Agr. 1-2, 9-40.

O'Neill J. (1997) Value pluralism, incommensurability and institutions, in: Foster J. (Ed.), Ecology, Policy and Politics: Human Well-Being and the Natural World, Routledge, London, pp. 75-88.

Pacini C., Wossink A., Giesen G., Vazzana C., Huirne R. (2003) Evaluation of sustainability of organic, integrated and conventional farming systems: a farm and field-scale analysis, Agr. Ecosyst. Environ. 95, 273-288.

Paelinck J.H.P. (1978) Qualifex, a flexible multiple criteria method, Econ. Lett. 1, 193-197.

Pannell D.J., Schilizzi S. (1999) Sustainable agriculture: a question of ecology, equity, economic efficiency or expedience? J. Sustain. Agr. $13,57-66$.

Park J., Seaton R.A.F. (1996) Integrative research and sustainable agriculture, Agr. Syst. 50, 81-100.

Pawlak Z. (1991) Rough Sets: Theoretical Aspects of Reasoning about Data. Kluwer, Dordrecht.

Phillis Y.A., Andriantiatsaholiniaina L.A. (2001) Sustainability: an illdefined concept and its assessment using fuzzy logic, Ecol. Econ. 37, 435-456.

Pillai C.R.S., Raju K.S. (1996) Ranking irrigation management alternatives by multicriterion analysis, Int. J. Water Resour. Dev. 12, 329 345.

Rehman T., Romero C. (1993) The application of the MCDM paradigm to the management of agricultural systems: some basic considerations, Agr. Syst. 41, 239-255.
Rigby D., Caceres D. (2001) Organic farming and the sustainability of agricultural systems, Agr. Syst. 68, 21-40.

Rogers M., Bruen M, (1998) Choosing realistic values of indifference, preference and veto thresholds for use with environmental criteria within ELECTRE, Eur. J. Oper. Res. 107, 542-551.

Rossing W.A.H., Meynard J.M., Van Ittersum M.K. (1997) Model-based explorations to support development of sustainable farming systems: case studies from France and the Netherlands, Eur. J. Agron. 7, 271-283.

Roubens M. (1982) Preference relations on actions and criteria in multicriteria decision making, Eur. J. Oper. Res. 10, 51-55.

Roy B. (1968) Classement et choix en présence de points de vue multiples (la méthode Électre), Rev. Fr. Informatique Recherche Opérationnelle 8, 57-75.

Roy B. (1985) Méthodologie Multicritère d'Aide à la Décision, Economica, Paris.

Roy B., Bouyssou D. (1993) Aide multicritère à la décision : Méthodes et cas, Economica, Paris.

Saaty T.L. (1980) The analytic hierarchy process, McGraw-Hill, New York.

Salminen P., Hokkanen J., Lahdelma R. (1998) Comparing multicriteria methods in the context of environmental problems, Eur. J. Oper. Res. 104, 485-496.

Schaller N. (1993) The concept of agricultural sustainability, Agr. Ecosyst. Environ. 46, 89-97.

Schärlig A. (1985) Décider sur plusieurs critères, Panorama de l'aide à la décision multicritère, Presses polytechniques et universitaires romandes, Lausanne.

Schmoldt D.L., Kangas J., Mendoza G.A. (2001) (Eds.), The Analytic Hierarchy Process in Natural Resource and Environmental Decision Making, Kluwer Academic Publishers, London.

Sebillotte M. (1990) Système de culture, un concept opératoire pour les agronomes, in: Combe L., Picard D. (Eds.), Un point sur les systèmes de culture, INRA éditions, Paris, pp. 165-196.

Shrestha R.K., Alavalapati J.R.R., Kalmbacher R.S. (2004) Exploring the potential for silvopasture adoption in South-central Florida: an application of SWOT-AHP method, Agr. Syst. 81, 185-199.

Smith C.S., McDonald G.T. (1998) Assessing the sustainability at the planning stage, J. Environ. Manage. 52, 15-37.

Steuer R.E. (1986) Multiple Criteria Optimization: Theory, Computation, and Application, Wiley, New York.

Stewart T.J., Losa F.B. (2003) Towards reconciling outranking and value measurement practice, Eur. J. Oper. Res. 145, 645-659.

Sulser T.B., Duryea M.L., Frolich L.M. (2001) A field practical approach for assessing biophysical sustainability of alternative agricultural systems, Agr. Syst. 68, 113-135.

Ten Berge H.F.M., Van Ittersum M.K., Rossing W.A.H., van de Ven G.W.J., Schans J., van de Sanden P.A.C.M. (2000) Farming options for The Netherlands explored by multi-objective modelling, Eur. J. Agron. 13, 263-277.

Tixier P., Malezieux E., Dorel M., Bockstaller C., Girardin P. (2007) Rpest- An indicator linked to a crop model to assess the dynamics of the risk of pesticide water pollution: Application to banana-based cropping systems, Eur. J. Agron. 26, 71-81.

Tré J.P., Lowenberg-Deboer J. (2005) ex ante economic analysis of alternative mulch-based management systems for sustainable plantain production in Southeastern Nigeria, Agr. Syst. 86, 52-75.

UK DTLR (2001) DTLR Multi-Criteria Analysis Manual, Department for Transport, Local Government and the Regions, UK, $145 \mathrm{p}$.

van der Werf H., Zimmer C. (1998) An indicator of pesticide environmental impact based on a fuzzy expert system, Chemosphere 36, 2225-2249. 
Van Huylenbroeck G., Damasco-Tagarino D. (1998) Analyzing crop choice of Philippine vegetable farmers with multicriteria analysis, J. Multi-Criteria Decision Anal. 7, 160-168.

Van Ittersum M., Ewert F., Heckelei T., Wery J., Alkan Olsson J., Andersen E., Bezlepkina I., Brouwer F., Donatelli M., Flichman G., Olsson L., Rizzoli A., van der Wal T., Wien J.E., Wolf J. (2007) Integrated assessment of agricultural systems a componentbased framework for the European Union (SEAMLESS), Agr. Syst. (in press)

Vereijken P. (1997) A methodical way of prototyping integrated and ecological arable farming systems (I/EAFS) in interaction with pilot farms, Eur. J. Agron. 7, 235-250.

Vincke P. (1989) L'aide multicritère à la décision, Éditions de l'Université de Bruxelles, Bruxelles.

Voogd H. (1983) Multicriteria Evaluation for Urban and Regional Planning, Pion, Ltd., London.
Wang X., Triantaphyllou E. (2006) Ranking irregularities when evaluating alternatives by using some ELECTRE methods, Omega, in press, available online 14 February 2006.

Weersink A., Jeffrey S., Pannell D. (2002) Farm-level modeling for bigger issues, Rev. Agr. Econ. 24, pp. 123-140.

Zanakis S.H., Solomon A., Wishart N. Dublish S. (1998) Multi-attribute decision making: A simulation comparison of selection methods, Eur. J. Oper. Res. 107, 507-529.

Zander P., Kächele H. (1999) Modelling multiple objectives of land use for sustainable development, Agr. Syst. 59, 311-325.

Zhang B., Zhang Y., Chen D., White R.E, Li Y. (2004) A quantitative evaluation system of soil productivity for intensive agriculture in China, Geoderma 123, 319-331.

Zhou P., Ang B.W., Poh K.L. (2006) Decision analysis in energy and environmental modeling: An update, Energy 31, 2604-2622.

Zupan B., Bohanec M., Demšar J., Bratko I. (1999) Learning by discovering concept hierarchies, Artif. Intell. 109, 211-242. 